\title{
Assessment of the FTO gene polymorphisms in male patients with metabolic syndrome
}

\author{
Ryszard Ślęzake, ${ }^{1, A-F}$, Przemysław Leszczyński, ${ }^{2, B-D, F}$, Magdalena Warzecha, ${ }^{1, B, C, F}$, \\ Łukasz Łaczmański $^{3,-F}$, Błażej Misiak ${ }^{1, A, C F}$ \\ ${ }^{1}$ Department of Genetics, Wroclaw Medical University, Poland \\ ${ }^{2}$ Department of Biology and Medical Parasitology, Wroclaw Medical University, Poland \\ ${ }^{3}$ Ludwik Hirszfeld Institute of Immunology and Experimental Therapy, Polish Academy of Science, Wrocław, Poland \\ A - research concept and design; $\mathrm{B}$ - collection and/or assembly of data; $\mathrm{C}$ - data analysis and interpretation; \\ $D$ - writing the article; $E$ - critical revision of the article; $F$ - final approval of the article
}

\section{Address for correspondence}

Błażej Misiak

E-mail:mblazej@interia.eu

Funding sources

The study was performed within Wroclaw Medical University statutory activities (ST-815).

Conflict of interest None declared

Received on November 7, 2016

Reviewed on March 23, 2017

Accepted on July 4, 2017

\begin{abstract}
Background. Accumulating evidence indicates the potential involvement of the FTO gene polymorphisms in the etiology of metabolic syndrome (MetS) and related disorders.

Objectives. In this study, we aimed to investigate whether the FTO gene polymorphisms are associated with the risk of MetS and its simple components in a homogeneous sample of males.

Material and methods. Anthropometric and biochemical parameters were assessed in $192 \mathrm{males}$. A total of 100 males met the National Cholesterol Education Program Adult Treatment Panel III (NCEP-ATPIII) criteria for a diagnosis of MetS. The following FTO gene polymorphisms were genotyped: rs1421085, rs17817449, rs1558902, and rs9939609.
\end{abstract}

Results. There were significant differences between participants with distinct rs9939609 genotypes with respect to waist-to-hip ratio (WHR) and the levels of total cholesterol. Individuals with the rs1421085 CC genotype had significantly higher levels of triglycerides compared to those with other corresponding genotypes. Participants with the rs1558902 AA genotype had significantly higher body mass index (BMI), WHR, as well as the levels of total cholesterol and triglycerides. There were no significant differences in genotype distribution allelic frequencies of all tested polymorphisms between individuals with MetS and control subjects.

Conclusions. Our results indicate that the genetic variation in the FTO gene might be related to single metabolic disturbances. However, the FTO gene polymorphisms are not associated with the risk of MetS.

Key words: metabolic syndrome, obesity, polymorphism, FTO gene

DOI

10.17219/acem/75676

Copyright

Copyright by Author(s)

This is an article distributed under the terms of the

Creative Commons Attribution Non-Commercial License

(http://creativecommons.org/licenses/by-nc-nd/4.0/) 


\section{Introduction}

Obesity is increasingly being recognized as one of the major health problems and social burdens with a potential impact on future generations. ${ }^{1}$ In 2014, the World Health Organization (WHO) revealed that more than 1.9 billion adults are overweight worldwide. Overweight and obesity can lead to a number of metabolic and cardiovascular adversities, such as dyslipidemia, insulin resistance and hypertension, which have been clustered into the condition called metabolic syndrome (MetS). It has been reported that MetS serves as the predictor of severe cardiovascular outcomes and type 2 diabetes. Indeed, it has been estimated that 2.8 million of deaths worldwide can be attributed to the consequences of being overweight or obese.

Several lines of evidence indicate the involvement of genetic and environmental factors, including cultural patterns of dietary habits and feeding behaviors, in the development of obesity and related conditions. In recent years, a special emphasis has been placed on the role of the FTO gene in the development of obesity. Indeed, a number of genome-wide association studies (GWASs) have revealed that single nucleotide polymorphisms (SNPs) located in intron 1 of the FTO gene confer the risk of obesity in European populations. On the basis of meta-analysis, Wang et al. also revealed that certain FTO SNPs (rs9939609, rs8050136 and rs1421085) were associated with the risk of MetS. ${ }^{2}$ The majority of more recent studies confirmed these findings. ${ }^{3-9}$ However, mechanisms mediating the impact of the FTO gene on the development of obesity and related phenotypes remain unclear. Given that these polymorphic variants are intronic, it has been postulated that the FTO SNPs act via interactions with genes located in their close proximity. ${ }^{10}$ Other potential mechanisms linking the FTO gene function with obesity include interactions with dopaminergic neurotransmission within the brain reward circuitry and ghrelin-mediated signaling, as well as the possible role of the FTO gene in the regulation of epigenetic processes. ${ }^{11}$

Interestingly, some studies have reported gender effects in the association between the FTO gene SNPs and obesityrelated phenotypes. For instance, in the study by SaldanaAlvarez et al., the rs1121980 polymorphism was associated with obesity in females only. ${ }^{12}$ Another study revealed that the effects of the rs17817449 polymorphism on body weight might be limited to males and postmenopausal women. ${ }^{13}$ Therefore, it might be hypothesized that studies investigating the relationship between the FTO SNPs and MetS indices should take into account possible gender effects. Thus, the aim of this study was to examine the effects of the FTO gene polymorphisms (rs1421085, rs17817449, rs1558902, and rs9939609) on the risk of MetS and its single components in a homogenous sample of male individuals.

\section{Material and methods}

\section{Subjects}

We recruited 192 males aged $39.7 \pm 10.2$ years. A diagnosis of MetS was established in 100 males based on the National Cholesterol Education Program Adult Treatment Panel III (NCEP-ATPIII) criteria. Other participants, with body mass index $(\mathrm{BMI})<25 \mathrm{~kg} / \mathrm{m}^{2}$, were included in the control group. Fasting levels of total cholesterol, low-density lipoproteins (LDL) and high-density lipoproteins (HDL), triglycerides, and glucose were determined using standard procedures. The following anthropometric parameters were measured: weight, height, BMI, waist circumference, hip circumference, and waist-to-hip ratio (WHR).

\section{Genotyping}

A multiplex polymerase chain reaction (PCR) assay was designed to amplify 4 fragments of FTO containing investigated SNPs (rs1421085, rs17817449, rs1558902, rs9939609). Multiplex PCR was performed with the Phire Hot Start II DNA Polymerase (Thermo Scientific, Waltham, USA). Briefly, the reaction mixture contained: $2 \mu \mathrm{L}$ of $\times 5$ reaction buffer (provides $1.5 \mathrm{mM} \mathrm{MgCl}_{2}$ in the final $\times 1$ concentration) (Thermo Scientific), $0.7 \mu \mathrm{L}$ of deoxynucleotides (dNTPs) (40 mM) (Fermentas, Burlington, Canada), $0.5 \mu \mathrm{L}$ of each primer $(10 \mathrm{mM})$ (Generi Biotech s.r.o., Hradec Králové, Czech Republic), $0.2 \mu \mathrm{L}$ of Phire Hot Start II DNA Polymerase, $1 \mu \mathrm{L}$ DNA, in a total volume of $10 \mu \mathrm{L}$.

Table 1. Genotype distributions and allelic frequencies of the FTO gene polymorphisms

\begin{tabular}{|c|c|c|c|c|}
\hline $\begin{array}{c}\text { FTO gene } \\
\text { polymorphism }\end{array}$ & $\begin{array}{l}\text { Patients } \\
\text { with MetS }\end{array}$ & Controls & $x^{2}$ & $p$-value \\
\hline $\begin{array}{l}\text { rs } 1421085 \\
\text { CC } \\
\text { CT } \\
\text { TT } \\
\text { C-allele } \\
\text { T-allele }\end{array}$ & $\begin{array}{c}n=100 \\
27(27.0) \\
46(46.0) \\
27(27.0) \\
100(50.0) \\
100(50.0)\end{array}$ & $\begin{array}{c}n=91 \\
33(36.3) \\
37(40.6) \\
21(23.1) \\
103(56.6) \\
79(43.4)\end{array}$ & 1.35 & 0.386 \\
\hline $\begin{array}{l}\text { rs17817449 } \\
\text { GG } \\
\text { GT } \\
\text { TT } \\
\text { G-allele } \\
\text { T-allele }\end{array}$ & $\begin{array}{c}n=100 \\
27(27.0) \\
52(52.0) \\
21(21.0) \\
106(53.0) \\
94(47.0)\end{array}$ & $\begin{array}{c}n=92 \\
32(34.8) \\
40(43.5) \\
20(21.7) \\
104(56.5) \\
80(43.5)\end{array}$ & 1.52 & 0.467 \\
\hline $\begin{array}{l}\text { rs1558902 } \\
\text { TT } \\
\text { TA } \\
\text { AA } \\
\text { T-allele } \\
\text { A-allele }\end{array}$ & $\begin{array}{c}n=100 \\
29(29.0) \\
45(45.0) \\
26(26.0) \\
103(51.5) \\
97(48.5)\end{array}$ & $\begin{array}{c}n=90 \\
36(40.0) \\
36(40.0) \\
18(20.0) \\
108(60.0) \\
72(40.0)\end{array}$ & 2.20 & 0.140 \\
\hline $\begin{array}{l}\text { rs9939609 } \\
\text { TT } \\
\text { TA } \\
\text { AA } \\
\text { T-allele } \\
\text { A-allele }\end{array}$ & $\begin{array}{c}n=100 \\
34(34.0) \\
45(45.0) \\
21(21.0) \\
113(56.5) \\
87(43.5)\end{array}$ & $\begin{array}{c}n=88 \\
38(43.2) \\
34(38.6) \\
16(18.2) \\
110(62.5) \\
66(37.5)\end{array}$ & 0.89 & 0.350 \\
\hline
\end{tabular}

Data expressed as the number of subjects (\%); MetS - metabolic syndrome. 
The reaction was performed in a PTC-200 thermal cycler (MJ Research Inc., St. Bruno, Canada) with the following reaction parameters: $95^{\circ} \mathrm{C}$ for $1 \mathrm{~min} 30 \mathrm{~s}, 35$ cycles at $95^{\circ} \mathrm{C}$ for $20 \mathrm{~s}, 60^{\circ} \mathrm{C}$ for $20 \mathrm{~s}, 72^{\circ} \mathrm{C}$ for $15 \mathrm{~s}$, and $72^{\circ} \mathrm{C}$ for $1 \mathrm{~min} 30 \mathrm{~s}$ final extension. Multiplex PCR products were checked for quality and yield by running $5 \mu \mathrm{L}$ in $2 \%$ agarose-Tris-borate-EDTA gel, stained Sybr Green and visualized on a UV light transilluminator. Multiplex PCR products were purified using enzymatic digestion. In the study, $1 \mu \mathrm{L}$ of multiplex PCR was treated with $1.5 \mu \mathrm{L}$ of Clean-up enzyme mix ( $1 \mathrm{U}$ of fast alkaline phosphatase and $10 \mathrm{U}$ of Exo1) at $37^{\circ} \mathrm{C}$ for $15 \mathrm{~min}$. SNaPshot analysis was performed using the SNaPshot Multiplex kit (Applied Biosystems, Woolston, Warrington, UK). Reactions were performed in a final volume of $5.5 \mu \mathrm{L}$, containing $2.5 \mu \mathrm{L}$ of purified multiplex PCR product, $2.5 \mu \mathrm{L}$ of SNaPshot Ready Multiplex Reaction Mix and $0.5 \mu \mathrm{L}$ of equimolar probe mix (each probe at $2 \mathrm{~mol} / \mathrm{L}$ final concentration). Multiplex single base extensions were carried out for 25 cycles with the following reaction parameters: $10 \mathrm{~s}$ at $96^{\circ} \mathrm{C}$, $5 \mathrm{~s}$ at $50^{\circ} \mathrm{C}$ and $30 \mathrm{~s}$ at $60^{\circ} \mathrm{C}$. SNaPshot products were then treated at $37^{\circ} \mathrm{C}$ for $1 \mathrm{~h}$ with $1 \mu \mathrm{L}$ of fast alkaline phosphatase $(1 \mathrm{U} / \mu \mathrm{L})$ (Fermentas International Inc., Burlington, Canada). Fast alkaline phosphatase was inactivated for $15 \mathrm{~min}$ at $75^{\circ} \mathrm{C}$. The labeled products were mixed with 9.5 $\mu \mathrm{L}$ of Hi-Di Formamide and $0.5 \mu \mathrm{L}$ of Genescan-120LIZ size standard (Applied Biosystems). They were then separated using a 15-minute run on an $\mathrm{ABI} 310 \mathrm{DNA}$ sequencer with POP-4 matrix (Applied Biosystems) and 10-second injection time. Fragment analyzes were performed on the Gene Marker software v. 1.85 (SoftGenetics, Centre County, State College, USA).

\section{Statistical analysis}

The Hardy-Weinberg (HWE) equilibrium was evaluated by comparing observed and expected genotype distributions using the $\chi^{2}$ test. The $X^{2}$ test was also used to compare the distribution of genotypes and allelic frequencies between patients with MetS and control subjects. Effects of distinct FTO genotypes on biochemical and anthropometric parameters were tested using the Kruskal-Wallis test. Adjustment for multiple testing was performed using Bonferroni correction, taking into account the number of tested polymorphisms. All tests were two-tailed with a 0.05 level of significance. Statistical analysis was performed using the STATISTICA software v. 12.5 (SPSS Inc., Chicago, USA).

\section{Results}

Genotype distributions for all polymorphisms genotyped in this study were in agreement with the HWE. There were no significant differences in genotype distributions and allelic frequencies between patients with
MetS and healthy controls (Table 1). The analysis of the FTO gene polymorphisms with respect to anthropometric and biochemical parameters in both groups (patients with MetS and healthy controls) is presented in Table 2. In both groups, the rs9939609 AA genotype was associated with a significantly higher WHR and total cholesterol levels compared to other corresponding genotypes. Additionally, this genotype was related to higher BMI at the trend level significance. The level of triglycerides was significantly higher in individuals with the rs1421085 CC genotype in comparison with those with other rs1421085 genotypes. Finally, the rs1558902 AA homozygotes had significantly higher BMI, WHR, total cholesterol, and triglycerides than subjects with other corresponding genotypes. However, none of these differences were significant after Bonferroni correction ( $\mathrm{p}>0.0125$ ). The FTO rs17817449 polymorphism was not significantly associated with biochemical and anthropometric parameters.

\section{Discussion}

The FTO gene is located on chromosome 16 and it consists of 9 exons; however, SNPs analyzed in our study are located in intron 1. The expression of the FTO gene has been described in the brain and adrenal glands. It has been demonstrated that the FTO gene exerts biological activity via the effects on DNA methylation of genes encoding transcription factors. ${ }^{14}$ Upregulated FTO gene expression has been reported mainly within hypothalamic nuclei, which accounts for energy expenditure. ${ }^{15}$ In addition, the expression of the FTO gene might be regulated by starvation and satiety signals. The FTO gene might also be involved in the regulation of hypothalamic-pituitary-adrenal axis functioning and lipolysis. ${ }^{15}$ It also has been found that it might impact the sympathetic nervous system regulating the cardiovascular system and blood pressure. ${ }^{16}$ Interestingly, the FTO gene expression might be regulated by estrogens, pointing to the widely-reported sex differences in obesity phenotypes. ${ }^{17}$

In this study, we found that neither of the tested FTO gene polymorphisms was associated with the risk of MetS development. However, we demonstrated that the FTO gene polymorphisms, except for the rs17817449 polymorphic variant, might impact certain metabolic parameters, including BMI and WHR, as well as the levels of total cholesterol and triglycerides. Although recent meta-analyses revealed that the FTO gene polymorphisms (rs9939609, rs8050136 and rs1421085) might be associated with the risk of MetS, authors indicated that ethnic differences and the use of various MetS criteria might impact effect sizes. ${ }^{2,9}$ Therefore, the association of the FTO gene polymorphisms might hold true only in certain populations, depending also on MetS conceptualization.

Our findings are in agreement with previous GWASs, showing that the FTO gene polymorphisms might confer the risk of MetS. Importantly, in the majority of previous 


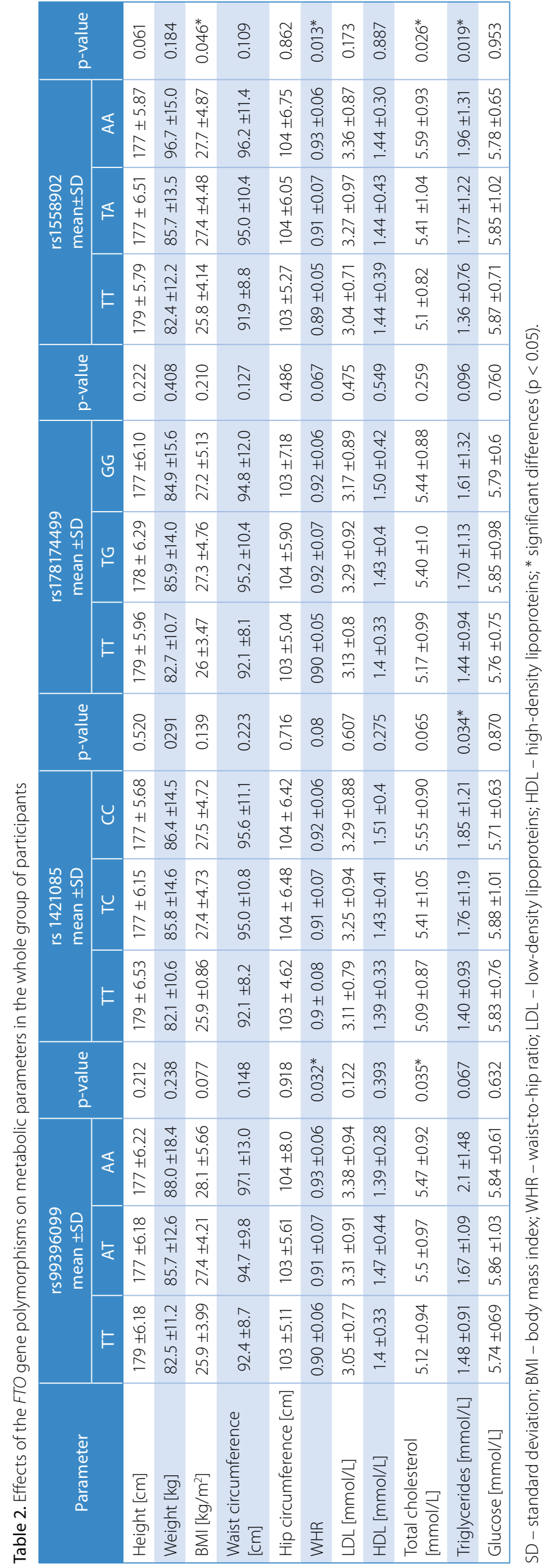

studies, the FTO gene polymorphisms were related to single metabolic parameters, including anthropometric measures and the levels of glucose, HDL or triglycerides, highlighting the potential involvement of this gene in the etiology of obesity. ${ }^{18-20}$ In agreement with our results, previous studies have repeatedly reported the association between the FTO rs9939609 polymorphism and BMI. ${ }^{19-21}$ More specifically, the A allele within this polymorphic site has been related to higher BMI. Similar results were also obtained by Al-Attar et al., who found the association between the FTO rs9939609 AA genotype and higher BMI (at the trend level significance) and WHR (significant association). ${ }^{22}$ In addition, there are studies showing the impact of this polymorphism on the risk of cardiovascular diseases and type 2 diabetes. ${ }^{18,23,24}$ Finally, in a study by Freathy et al., this polymorphism was associated with higher levels of glucose and triglycerides as well as lower levels of HDL that appeared due to the effect on BMI. ${ }^{25}$

Similar results have been reported with respect to other SNPs analyzed in this study. Regarding rs1558902, no significant effects on MetS risk have been demonstrated. However, this SNP has been related to higher BMI and fasting levels of glucose. ${ }^{6,26}$ Other SNPs tested in our study (rs1421085 and rs17817449) have been found to impact BMI and WHR. Interestingly, in the study by Harbron et al., risk alleles of the rs1421085 and rs17817449 SNPs predicted poor eating behaviors (higher hunger, internal locus of hunger and emotional disinhibition) and a higher intake of high fat foods and refined starches. ${ }^{27}$

Our study has some limitations that should be taken into account. Firstly, our sample size was relatively low and thus it cannot be excluded that negative results with respect to the impact of the FTO gene SNPs on MetS risk or other metabolic parameters are simply due to a lack of statistical power. Another point is that a number of variables connected to lifestyle factors and eating behaviors have not been included in this study. Therefore, more precise conclusions on causality cannot be established. Another point is that our analysis was confined to the assessment of a limited number of metabolic parameters, restricting the conclusions regarding the biological mechanisms that might mediate the effects of the FTO gene SNPs on obesity and related outcomes. Finally, caution should be taken in interpreting the association between the FTO SNPs and anthropometric or biochemical parameters in the whole group of participants, since significant results of the statistical analysis that was unadjusted for multiple testing were not significant after Bonferroni correction.

In conclusion, the results of our study indicate that the FTO gene might impact single metabolic parameters, rather than a clustering of cardio-metabolic disturbances conceptualized as MetS. Future studies should investigate the effects of the FTO SNPs on obesity and related conditions in bigger samples with comprehensive assessment of cardiometabolic parameters, environmental factors and eating behaviors. 


\section{References}

1. Hanson M, Gluckman $P$, Bustreo F. Obesity and the health of future generations. Lancet Diabetes Endocrinol. 2016;4(12):966-967.

2. Wang H, Dong S, Xu H, Qian J, Yang J. Genetic variants in FTO associated with metabolic syndrome: A meta- and gene-based analysis. Mol Biol Rep. 2012;39:5691-5698.

3. de Luis DA, Aller R, Conde R, Izaola O, de la Fuente B, Sagrado MG. Relation of the rs9939609 gene variant in FTO with metabolic syndrome in obese female patients. J Diabetes Complications. 2013;27: 346-350.

4. Elouej S, Nagara M, Attaoua R, et al. Association of genetic variants in the FTO gene with metabolic syndrome: A case-control study in the Tunisian population. J Diabetes Complications. 2016;30:206-211.

5. Hu YH, Liu JM, Zhang M, et al. Association between polymorphisms of fat mass and obesity-associated gene and metabolic syndrome in Kazakh adults of Xinjiang, China. Genet Mol Res. 2015;14:1459714606.

6. Kawajiri T, Osaki Y, Kishimoto T. Association of gene polymorphism of the fat mass and obesity associated gene with metabolic syndrome: A retrospective cohort study in Japanese workers. Yonago Acta Med. 2012;55:29-40.

7. Liguori R, Labruna G, Alfieri A, Martone D, Farinaro E, Contaldo F. The FTO gene polymorphism (rs9939609) is associated with metabolic syndrome in morbidly obese subjects from southern Italy. $\mathrm{Mol}$ Cell Probes. 2014;28:195-199.

8. Yang J, Liu J, Li W, Li X, He Y, Ye L. Genetic association study with metabolic syndrome and metabolic-related traits in a cross-sectional sample and a 10-year longitudinal sample of Chinese elderly population. PLoS ONE. 2014;9:e100548.

9. Zhou D, Liu H, Zhou M, et al. Common variant (rs9939609) in the FTO gene is associated with metabolic syndrome. Mol Biol Rep. 2012;39: 6555-6561.

10. Merkestein M, Sellayah D. Role of FTO in adipocyte development and function: Recent insights. Int J Endocrinol. 2015; Article ID 521381.

11. Tung YC, Yeo GS, O'Rahilly S, Coll AP. Obesity and FTO: Changing focus at a complex locus. Cell Metab. 2014;20:710-718.

12. Saldana-Alvarez Y, Salas-Martinez MG, Garcia-Ortiz H, et al. Genderdependent association of FTO polymorphisms with body mass index in Mexicans. PLoS ONE. 2016;11:e0145984.

13. Hubacek JA, Pitha J, Adamkova V, Lanska V, Poledne R. A common variant in the FTO gene is associated with body mass index in males and postmenopausal females but not in premenopausal females. Czech post-MONICA and 3PMFs studies. Clin Chem LabMed. 2009;47: 387-390.
14. Wu Q, Saunders RA, Szkudlarek-Mikho M, Serna Ide L, Chin KV. The obesity-associated FTO gene is a transcriptional coactivator. Biochem Biophys Res Commun. 2010;401:390-395.

15. Yeo GS, O'Rahilly S. Uncovering the biology of FTO. Mol Metab. 2012; 1(1-2):32-36.

16. Fawcett KA, Barroso I. The genetics of obesity: FTO leads the way. Trends Genet. 2010;26(6):266-274.

17. Zhang Z, Zhou D, Lai Y, Liu Y, Tao X, Wang Q. Estrogen induces endometrial cancer cell proliferation and invasion by regulating the fat mass and obesity-associated gene via PI3K/AKT and MAPK signaling pathways. Cancer Lett. 2012;319:89-97.

18. Binh TQ, Phuong PT, Nhung BT, Thoang DD, Lien HT, Thanh DV. Association of the common FTO-rs9939609 polymorphism with type 2 diabetes, independent of obesity-related traits in a Vietnamese population. Gene. 2013;513(1):31-35.

19. Dusatkova L, Zamrazilova H, Sedlackova B, Vcelak J, Hlavaty P, Aldhoon Hainerova I. Association of obesity susceptibility gene variants with metabolic syndrome and related traits in 1,443 Czech adolescents. Folia Biol (Praha). 2013;59(3):123-133.

20. Hunt SC, Stone S, Xin Y, Scherer CA, Magness CL, ladonato SP. Association of the FTO gene with BMI. Obesity (Silver Spring). 2008;16: 902-904.

21. Scuteri A, Sanna S, Chen WM, Uda M, Albai G, Strait J. Genome-wide association scan shows genetic variants in the FTO gene are associated with obesity-related traits. PLoS Genetics. 2007;3:e115.

22. Al-Attar SA, Pollex RL, Ban MR, et al. Association between the FTO rs9939609 polymorphism and the metabolic syndrome in a nonCaucasian multi-ethnic sample. Cardiovasc Diabetol. 2008;7:5.

23. Karaderi T, Drong AW, Lindgren CM. Insights into the genetic susceptibility to type 2 diabetes from genome-wide association studies of obesity-related traits. Curr Diab Rep. 2015;15:83.

24. Liu C, Mou S, Pan C. The FTO gene rs9939609 polymorphism predicts risk of cardiovascular disease: A systematic review and metaanalysis. PLoS ONE. 2013;8:e71901.

25. Freathy RM, Timpson NJ, Lawlor DA, et al. Common variation in the FTO gene alters diabetes-related metabolic traits to the extent expected given its effect on BMI. Diabetes. 2008;57:1419-1426.

26. Hotta, K, Nakata Y, Matsuo T, et al. Variations in the FTO gene are associated with severe obesity in the Japanese. J Hum Genet. 2008;53: 546-553.

27. Harbron J, van der Merwe L, ZaahI MG, Kotze MJ, Senekal M. Fat mass and obesity-associated (FTO) gene polymorphisms are associated with physical activity, food intake, eating behaviors, psychological health, and modeled change in body mass index in oveweight/ obese Caucasian adults. Nutrients. 2014;6(8):3130-3152. 
